\title{
INTEGRAÇÃO DISCIPLINAR E TOTALIDADE: UM DIÁLOGO ENTRE A INTERDISCIPLINA E A DIALÉTICA
}

Fabrizio Cândida dos Santos ${ }^{1}$

\section{Resumo}

A proposta interdisciplinar deste trabalho se funda nas bases ontológicas constitutivas do ser social, em seu devir histórico, colocando a questão para além da filosofia do sujeito. Não se trata de interdisciplinar por uma metodologia dialética, mas interdisciplinar a partir da natureza dialética da realidade. A divisão disciplinar da ciência revela um particular modo de visualizar a totalidade dos plexos relacionais da realidade. A disciplina racionaliza, fragmenta. A partir dos fragmentos representativos fundam-se as teses, as proposições: nascem os discursos científicos. Mas a efervescência da realidade teima em não se conter na ordem estabelecida pela ciência. A faticidade do real, com suas conexões, seus antagonismos, estabelece constante e erraticamente novas formas de objetivação que não se acomodam nas raias estreitas e estáticas dos ramos científicos. É sobre esse ponto de inflexão que a dialética pode contribuir para o avanço interdisciplinar, descortinando as nuanças do real, sua unidade concreta e contraditória.

Palavras-chave: interdisciplinaridade; dialética; totalidade.

\begin{abstract}
The interdisciplinary approach of this work is founded on the constitutive ontological bases of social being in its historical development, putting the issue beyond the philosophy of the subject. It is not interdisciplinary in a dialectical methodology, but interdisciplinary from the dialectical nature of reality. The disciplinary division of science reveals a particular way of viewing all the relational reality plexus. Discipline streamlines, fragments. From representative fragments merge up the theses, propositions: the scientific discourse arises. But the effervescence of reality insists on not be contained in the order established by science. The real facticity, with their connections, their antagonisms, provides constant and erratically new forms of objectification that do not accommodate the narrow and static streaks of scientific branches. It is on this point of inflection that dialectic can contribute to interdisciplinary breakthrough, revealing the real nuances, its concrete and contradictory unity.
\end{abstract}

keywords: interdisciplinarity; dialectic; totality.

\footnotetext{
${ }^{1}$ Possui mestrado em Sociedade, Cultura e Fronteira, pela Universidade Estadual do Oeste do Paraná (UNIOESTE).
} 


\section{Introdução}

O presente trabalho tem por objeto a análise de um possível diálogo entre a interdisciplina e a dialética. Dialogar já é, em si, uma proposição dialética, remetendo à tradição platônica da dialética discursiva. E dialogar é também discursar, remetendo ao discurso em geral, e particularmente ao discurso científico. Embora a dialética pareça subversiva à ordem, ao levar a cabo os antagonismos propositivos, é a detentora das chaves de acesso à realidade, posto ser a representação conceitual das categorias formatadas à concretude da vida: é a partir da unidade dialética do real que se pode constituir uma análise interdisciplinar. A necessidade interdisciplinar deriva desse intricado jogo de conexões, de desarranjos e de reconexões em que se funda a realidade, no curso da história. E a dialética é a conceptualização dessa dinâmica, oportunizando a emergência das leis que governam a totalidade do concreto.

A divisão disciplinar, em especial na tradição brasileira, tem sido apontada como uma patologia do saber (JAPISSU, 1976). Nesse sentido, a interdisciplinaridade poderia ser tomada como a cura desse mal. Não obstante, quer parecer que nem a disciplinaridade, em si, seja um mal, nem a interdisciplinaridade o remédio. Mesmo porque é dessa mesma tradição a derivação da interdisciplina da disciplina (FAZENDA, 2008), o que conduziria a uma circularidade do problema, e não a sua solução. $\mathrm{O}$ verdadeiro problema está na maneira pela qual tanto a disciplina quanto a interdisciplina foram construídas. Reduzidas a uma mera questão gnoseológica, pensadas por um sujeito cognoscente abstrato, que se isola do mundo para conceber, a priori, a racionalidade que legislará a realidade. Estabelece-se, assim, uma lógica a priori, vazia, destituída da práxis, a pretexto de constituir uma validade universal para as verdades fundantes do conhecimento. A materialidade do sujeito cognoscente desaparece, e com ela esgota-se toda ontologia em gnoseologia. Esse modo de pensar a disciplinaridade leva a equívocos quanto à formulação e ao alcance da interdisciplinaridade. De fato, tanto Japissu (2006), quanto Fazenda (2001) colocam a questão interdisciplinar no âmbito subjetivo: trata-se de uma atitude interdisciplinar. Verifica-se que o ponto de inflexão continua a ser, tal como na disciplinarização posta pela filosofia do sujeito, o pesquisador, seus critérios e sua metodologia. Ter uma nova atitude diante da questão do conhecimento, como apregoa Fazenda (2001) implica dizer que a interdisciplinaridade está situada no campo da gnoseologia, e está na dependência de um sujeito cognoscente que vá adotar uma conduta epistemológica revolucionária, donde sobressairá a interdisciplinaridade, como se esta se 
tratasse simplesmente de uma marca pessoal do autor da pesquisa (FAZENDA, 1994). Daí o erro de fundamentar a interdisciplina na parceria, buscando-se um diálogo com outras formas de saber (FAZENDA, 1994), sem antes buscar uma parceria com a própria realidade subjacente. Assim, justifica-se a busca de novas perspectivas para a colocação do problema. Isto porque não se pode pretender reduzir a questão da interdisciplina a uma mera questão de atitude individual, mas sim encará-la com uma necessidade, uma premência do real da qual desborda uma atitude social, em consonância com sua generidade. A atitude de um sujeito que reflita as condições reais de sua existência e de sua pesquisa, bem como a de seu objeto do saber; enfim, situar a questão no âmbito ontognoseológico, tomada esta relação em suas bases materiais, pressupondo que tanto objeto quanto sujeito são produtos da história. Como bem assentam Jantsch e Bianchetti (2008), a história cria, recria e faz evanescer os objetos a que se propõe conhecer. Esses pores, repores e evanescimentos são, em verdade, fruto das conexões, reconexões e desconexões dialéticas das categorias, que se (des) estabelecem, formando as redes de totalidades do real. Daí a necessidade de abordagem interdisciplinares, quando os objetos, outrora postos, sofrem desgastes, erosões, depreciações, acréscimos, reconexões, sedimentações, etc. Como apontado por Frigoto (2008), que a abordagem interdisciplinar não caracteriza uma arbitrariedade racional e abstrata, mas sim uma necessidade decorrente da própria constitutividade do ser social. Se buscar a raiz dessa constitutividade e confrontá-la com a exigência interdisciplinar é uma necessidade, está fundamentada também a problematização do presente trabalho.

\section{INTERDISCIPLINARIDADE, DIALÉTICA E TOTALIDADE.}

A interdisciplinaridade está posta na literatura como necessidade. A percepção da necessidade tem variado de acordo com a orientação tomada por seus defensores. Seria uma necessidade gnoseológica ou ontológica? Ou ambas? Fundamentada no âmbito da filosofia do sujeito, a interdisciplina resta reduzida à mera reacomodação de objetos cognoscíveis e realizada pela aproximação epistemológica das áreas do saber onde se pretende a visão interdisciplinar. A interdisciplina, assim posta, situa-se no campo da gnoseologia fincada em bases kantistas. Ao revolucionar copernicamente o modo de conhecer do homem, Kant fez também recuar a natureza ontológica do conhecimento. O sujeito cognoscente transcendental de Kant é um ator passivo de visão ativa, vale dizer, um sujeito que não interfere na realidade, mas a legisla as leis de 
compreensão dessa realidade. Gravitando em torno do sujeito, os objetos são reconhecidos em conformidade com categorias transcendentais inerentes à racionalidade humana. Nesse passo, o objeto cognoscível é determinado pelo sujeito no ato de conhecer, contém as "digitais" humanas em sua constituição. Essa categorização transcendental, segundo Kant (2009), é o que torna possível o conhecimento: a possibilidade do conhecimento se dá graças à existência de condicionantes transcendentais, que não estão postas na realidade, mas na própria natureza racional humana. Essas categorias sem história são as responsáveis pela determinação da forma dos fenômenos, ordenando a realidade que se nos chega pela sensibilidade provocada pelos objetos do conhecimento. Os objetos do conhecimento são meras representações da sensibilidade humana, pelo que o que se conhece são essas representações, e não a coisa-em-si, que permanece desconhecida. Embora o conhecimento só se desvele por ocasião da experiência, vez que, de acordo com Kant (2009), não há conhecimento que seja cronologicamente anterior à experiência, há uma anterioridade lógica dos princípios que norteiam o conhecimento e a experiência, tornando-os independentes. A razão pura apenas ordena formalmente a sensibilidade provocada pela realidade. Assim, o conhecimento é uma operação puramente mental e que se desenvolve basicamente pelas faculdades inerentes ao próprio sujeito cognoscente: a faculdade de receber representações, ou receptividade, e a faculdade de conhecer os objetos por meio das representações, ou entendimento. O conhecimento é o resultado do entrelaçamento das representações e de seu entendimento, ou, indo mais além, do entrelaçar das intuições, que determinam a forma pela qual os objetos são percebidos pelo sujeito (intuições puras), e pelos conceitos, que determinam a forma de pensamento de um objeto em geral (conceitos puros). Por isso, para Kant (2009), não há intuição sem conceito, bem como não há conceito sem intuição: os conceitos sem as intuições seriam vazios; as intuições sem os conceitos seriam cegas.

O transcendentalismo kantiano, ao excluir de sua ocupação a pertinência ontológica, acaba por eliminar também parte essencial para a construção do pensamento e conhecimento humanos. Ao tentar “(...) fundamentar a realidade partindo da capacidade de conhecimento, e não fundar o conhecimento partindo do ser (...)" (LUCKÁCS, 2010, P. 53), Kant não só deforma a compreensão do conhecimento como também suprime a condição objetiva do conhecimento, que são justamente as inter-relações do ser com o seu meio e com seu alter. O transcendentalismo kantiano, e suas variações, turva a correta compreensão da faculdade humana cognoscente e também a própria construção da ciência. Sobre a construção do pensamento humano na modernidade, Foucault (2000, p.347), diz que "A produção, a vida, a linguagem - não se devem 
buscar aí os objetos que se tivessem, como que por seu próprio peso e sob o efeito de uma insistência autônoma, imposto do exterior a um conhecimento que durante um tempo por demais longo os negligenciaria". Para Foucault (2000, p. 346), o que diferencia o pensamento clássico do pensamento da modernidade não é a “(...) descoberta de objetos desconhecidos como o sistema gramatical do sânscrito, ou a relação, no ser vivo, entre as disposições anatômicas e os planos funcionais, ou ainda o papel econômico do capital". O que mudou, segundo Foucault (2000), foi o próprio saber, o modo de ser prévio e indiviso entre sujeito cognoscente e objeto cognoscível. O deslocamento do objeto de ocupação no campo da Economia, por exemplo, substituindo-se a troca pela produção deriva dessa ruptura, ao nível arqueológico, das configurações próprias da positividade da Economia, originando-se, a partir de então, novos objetos cognoscíveis: “Adam Smith não inventou, portanto o trabalho como conceito econômico (...) nem lhe faz desempenhar um papel novo" (FOUCAULT, 2000, p. 305). Sob esse prisma, pode-se levar a crer que se nas análises econômicas de Aristóteles se encontram discursos sobre a escravatura por natureza; se os fisiocratas viam na produção agrícola a fonte de riqueza; ou se para Smith a fonte geratriz de riqueza é o trabalho, tal se deve menos à realidade subjacente que a movimentos de consciência. Não seriam o sistema escravocrata da Grécia antiga, ou a estrutura agrícola da França do século XVIII, ou o nascimento da indústria manufatureira na Inglaterra que determinaram a produção científica sobre os respectivos temas econômicos, mas sim o jogo e o papel das representações no estabelecimento de uma ordem. A posição de Foucault é insustentável.

A correta compreensão da cientificidade passa pela percepção marxiana acerca das categorias - formas do ser, determinações da existência - e a partir das interações do ser cognoscente com seu ambiente e com seu alter que emergem toda a forma de conhecimento. De fato é a práxis humana que constitui necessariamente o ponto de partida para todo o pensamento humano (LUKÁCS, 2010). Mas com isso não se quer dizer que o conhecimento humano seja um produto mecânico das condições materiais que permeiam a vida humana, mas sim que essa esfera é ineliminável na construção do sujeito cognoscente. A crítica weberiana ao reducionismo monista do conhecimento às causas econômicas (WEBER, 2006) tem sua razão quando toma em conta as concepções formuladas pelo marxismo ortodoxo e messiânico. Mas Weber (2006) incide nos mesmos erros do transcendentalismo abstrato ao tentar solucionar a questão da objetividade nas Ciências Sociais. Ao encartar que a realidade é caótica, ante a infinitude de elementos particulares que a compõe, Weber (2006) prega que o conhecimento se reduz a uma pequena parcela da 
realidade, eleita valorativamente pelo sujeito cognoscente, ao qual cabe estabelecer uma ordem sob um prisma de significação, por meio de um conhecimento nomológico, isto é, conhecimento das regularidades das conexões causais. Nesse passo, o objeto da ciência não são as conexões entre coisas, mas sim conexões conceituais entre os problemas. Há diversos pontos obscuros na percepção weberiana, a começar pela confusão entre caoticidade e infinitude. $O$ fato de haver uma infinitude de elementos que compõem a realidade não a torna caótica. Ora, o caos é o mais alto nível de entropia: como então buscar "regularidades" no caos? Mais ainda, ao colocar ênfase na escolha do sujeito sobre a parcela da realidade a ser pesquisada, Weber (2006) olvida-se de que essa valoração não é simplesmente individual, mas fruto da inserção desse sujeito na realidade. Não se trata de uma atitude individual, mas apenas singular, tomada em face do peso dos fatos que se lhe apresentam. O conhecimento não é um produto individual, mas social. Por fim, ao preterir as conexões objetivas, Weber (2006) situa-se no campo das reduções fenomênicas, conduzindo à impossibilidade de conhecimento da coisa-em-si. Essa oposição entre conhecimento e realidade corresponde à fratura do sujeito cognoscente e sua práxis, cujo resultado é o estabelecimento de um modo de conhecer fragmentado em disciplinas isoladas, que não se comunicam entre si e com a própria realidade que pretendem explicar. Daí a imperiosa necessidade de superação dos paradigmas da disciplinaridade e da interdisciplinaridade impostas pelo transcendentalismo abstrato e pelo positivismo. Não se pode pretender solucionar o requerimento da interdisciplina pela simples aproximação das áreas disciplinares. Ora, se a interdisciplina é uma exigência praxiológica, fundada nas contínuas mutações da realidade, parece óbvio que a realidade não pode ser ignorada nesse processo. A busca pela interdisciplina não pode se dar no sujeito cognoscente, simplesmente, mas antes na recíproca exigência dialética de sujeito e objeto, dentro de um contexto de produção social. É tanto o modo como o sujeito se projeta intencionalmente na realidade, como também o modo pelo qual realidade se põe diante dessa projeção.

Como bem assinalado por Marx (2012) "Mas esse compreender não consiste, como pensa Hegel, em reconhecer por toda a parte as determinações do conceito lógico, mas em apreender a lógica específica do objeto específico". A compreensão envolve a "apreensão" da legalidade objetiva, vale dizer, é tanto o ato do sujeito cognoscente que se lança ativamente à concretude da realidade, e também a própria realidade que se dispõe em sua lógica ao sujeito cognoscente. Assim, é possível afirmar com Lukács (2010) que é da interação desses dois mundos essenciais - o mundo do ser e de sua atividade prática e o mundo das objetividades dadas, socialmente mediadas - é que 
emerge a consciência, como precondição indispensável à adaptação do homem a seu ambiente: “ $A$ consciência é o produto de determinado modo de ser do ser social (...)” (LUKÁCS, 2010, p. 261). A emergência da consciência assinala o momento culminante da ontologização do ser social, fundada em sua atividade laborativa que se opera sobre, sob e pelas legalidades objetivas existentes. A tomada de consciência, e a cientificidade dela decorrente, não pode ser vista como um processo isolado da práxis, da totalidade concreta da realidade. A consciência, a cientificidade, são formadas a partir da realidade, a ela se destinam e fazem parte mesmo dela. São-lhe ao mesmo tempo espelho e reflexo. O requerimento da interdisciplinaridade deve ser fundamentado, portanto, na necessidade ontológica do ser social, e sua busca deve se dar na totalidade concreta da realidade, nas intermináveis conexões e desconexões que formam o tecido do real e da qual faz parte o sujeito cognoscente.

É preciso certificar, entretanto, que totalidade não significa a tomada em conta da totalidade dos fatos, mas sim da "realidade como um todo estruturado, dialético, no qual ou do qual um fato qualquer pode vir a ser compreendido" (KOSIK, 2011, p. 44). Não significa esgotar a infinitesimal possibilidade do real, mas evolver a realidade tomada a partir de sua constitutividade infinita. Somente a compreensão da realidade como unidade dialeticamente estruturada é capaz de fornecer as vias de acesso a essa mesma realidade e é a chave para a reconstrução da ciência sob o paradigma da interdisciplina, pois que essa compreensão é a única capaz de desvelar a dinâmica das infinitas articulações estruturais que se formam e se dissolvem continuamente. Assim, a interdisciplinaridade não é apenas exigência gnoseológica, mas também uma exigência ontológica: “As tentativas para criar uma nova ciência unitária tem origem na constatação de que a própria realidade, na sua estrutura, é dialética" (KOSIK, 2011, p. 45). A interdisciplinaridade não é aproximação entre especialistas, e sim aproximação à realidade. Kosik (2011, p. 45) afirma que " $A$ diferenciação da ciência (...) leva, ao contrário, com seus efetivos resultados e consequências, a sempre mais profundo descobrimento e a maior conhecimento da unidade do real". Quanto maior a proximidade da realidade, maior será a capacidade da ciência de criar e recriar seus campos disciplinares e interdisciplinares, sem que isso represente uma fratura da realidade.

Nesse passo, é papel da ciência fazer emergir, na consciência, as totalidades concretas, as articulações dialéticas que compõem o tecido do real. Essa é uma diferença essencial entre a concepção científica determinada nos moldes da filosofia do sujeito, para a qual a investigação científica deve basear-se (inda que não exclusivamente) em tipos ideais e a concepção dialética da 
cientificidade, que busca descortinar a essência constitutiva da realidade. No primeiro caso, as formulações científicas são mediadas por modelos obtidos “(...) mediante a acentuação unilateral de um ou vários pontos de vista, e mediante o encadeamento de grande quantidade de fenômenos isoladamente dados, difusos e discretos (...) e que se ordenam segundo pontos de vista unilateralmente acentuados" (WEBER, 2006, p. 73). No segundo "O conhecimento do sujeito só é possível na base da atividade do próprio sujeito sobre o mundo; o sujeito só conhece o mundo na proporção em que nele intervém ativamente (...)" (KOSIK, 2011, p. 183). Essa distinção trata de uma questão fundamental, como acentuado por Piaget (1973), pois coloca em evidência o problema da natureza das estruturas: se meros modelos, as estruturas são apenas instrumentos que dependem da lógica do observador, o qual mede a realidade não pela medida do sujeito, mas sim por sua própria medida; do contrário, se as estruturas são ínsitas à realidade estudada, correspondem às estruturas dos próprios sujeitos inseridos em sua realidade. A dialética materialista expõe a nudez da realidade, ao colocar em evidência suas estruturas constitutivas.

\section{Conclusão}

Em conclusão, a interdisciplinaridade deve ser compreendida como necessidade da práxis humana e sua busca deve se dar pela apreensão da realidade como totalidade dialeticamente articulada. A interdisciplinaridade só conseguirá cumprir seu objetivo de compreensão da realidade na medida em que se realizar ontognoseologicamente, na correlação entre o sujeito cognoscente e suas objetivações. A simples aproximação de campos epistêmicos não é capaz de produzir interdisciplina, mas apenas um amontoado de métodos e conceitos destituídos de significação. A verdadeira interdisciplina é aquela talhada à concretude da vida. A interdisciplinaridade põe-se como uma das formas de mediação do diálogo do ser humano com sua própria generidade e de suas relações com a natureza que lhe é circundante e constitutiva. Derivando a interdisciplinaridade de uma percepção dialética, guarda-se-lhe os traços essenciais desta, permitindo a construção de uma interdisciplinaridade construtiva e dialógica. Uma interdisciplinaridade de conceptualidade aberta, capaz de ordenar inteligentemente todas as idiossincrasias e os matizes que compõem a realidade.

\section{Referências bibliográficas}


FAZENDA. I. C. A. 1994. Interdisciplinaridade: história, teoria e pesquisa. $7^{\text {a }}$ edição. Campinas: Papirus. 2008. O Que É Interdisciplinaridade? São Paulo: Cortez.

FRIGOTO, G. 2008. A Interdisciplinaridade como Necessidade e como Problema nas Ciências Sociais. In: JANTSCH, A. P., BIANCHETTI, L organizadores. Interdisciplinaridade: para além da filosofia do sujeito. $8^{\mathrm{a}}$ edição. Petrópolis: Vozes.

FOUCAUlT, M. 2000. As Palavras e as coisas. Tradução de Salma Tannus Muchail. $8^{a}$ edição. São Paulo: Martins Fontes.

HEGEL, G. W. Friedrich. 1999. Fenomenologia do Espírito. $4^{\text {a }}$ edição, parte 1 e 2. Petrópolis: Vozes.

JANTSCH, A. P., BIANCHETTI, L. 2008. Imanência, História e Interdisciplinaridade. In: JANTSCH, A. P., BIANCHETTI, L organizadores. Interdisciplinaridade: para além da filosofia do sujeito. $8^{\mathrm{a}}$ edição. Petrópolis: Vozes.

JAPISSU, H. 1976 Interdisciplinaridade e Patologia do Saber. Rio de Janeiro: Imago.

KANT. I. 2009. Crítica da Razão Pura. Tradução de Lucimar Coghi Anselmi e Fulvio Lubisco. São Paulo: Martin Claret.

KOSIK, K. 1976. Dialética do Concreto. Tradução de Célia Neves e Alderico Toríbio. $2^{a}$ edição. Rio de Janeiro: Paz e Terra.

LUKÁCS, G. 2010. Prolegômenos para uma Ontologia do Ser Social. Tradução de Lya Luft Rodinei Nascimento. São Paulo: Boitempo.

MARX, K. 2012. Crítica da Filosofia do Direito de Hegel. Tradução de Rubens Enderie e Leonardo de Deus. São Paulo: Botempo.

PIAGET, J. 1973. Problemas Gerais de Investigação Interdisciplinar e Mecanismos Comuns. Tradução de Maria de Barros. Lisboa: Bertrand.

WEBER, M. 2006. A “Objetividade do Conhecimento Científico. Tradução de Gabriel Cohn. São Paulo: Editora Ática. 